\title{
Proteomic profiling of lymphocytes in autoimmunity, inflammation and cancer
}

\author{
Jiebai Zhou ${ }^{1 \dagger}$, Zhitu Zhu ${ }^{3+}$, Chunxue Bai ${ }^{1,2}$, Hongzhi Sun ${ }^{3^{*}}$ and Xiangdong Wang ${ }^{1,2^{*}}$
}

\begin{abstract}
Lymphocytes play important roles in the balance between body defense and noxious agents involved in a number of diseases, e.g. autoimmune diseases, allergic inflammation and cancer. The proteomic analyses have been applied to identify and validate disease-associated and disease-specific biomarkers for therapeutic strategies of diseases. The proteomic profiles of lymphocytes may provide more information to understand their functions and roles in the development of diseases, although proteomic approaches in lymphocytes are still limited. The present review overviewed the proteomics-based studies on lymphocytes to headlight the proteomic profiles of lymphocytes in diseases, such as autoimmune diseases, allergic inflammation and cancer, with a special focus on lung diseases. We will explore the potential significance of diagnostic biomarkers and therapeutic targets from the current status in proteomic studies of lymphocytes and discuss the value of the currently available proteomic methodologies in the lymphocytes research.
\end{abstract}

Keywords: Proteomics, Lymphocyte, Autoimmune, Allergic inflammation, Cancer

\section{Introduction}

Lymphocytes play central and pivotal roles in immune defense mechanisms against pathogens and controls of the immune responses, including protective responses against pulmonary pathogens and lung diseases, e.g. asthma, sarcoidosis, idiopathic pulmonary fibrosis, or alveolitis [1-4]. The emergence of genomics, proteomics, and bioinformatics allows defining gene expression and/or protein profile in lymphocytes to furthermore understand interactions between the components within targeted signaling network, even though a number of challenges still exist. The protein expression and post-translational modifications profiled by proteomics can explore functional interactions between proteins and develop disease-specific biomarkers by integrating with clinical informatics [5-7]. Proteomic tools and strategies are used to elucidate mechanisms and function of lymphocyte signaling and biology, including glycoprotein, phosphoprotein, membrane protein, single

\footnotetext{
*Correspondence: hongzhisun@hotmail.com; xiangdong.wang@

clintransmed.org

${ }^{\dagger}$ Equal contributors

${ }^{3}$ Center for Cancer Molecular and Cellular Therapies, The First Affiliated

Hospital of Liaoning Medical University, Liaoning, China

'Department of Pulmonary Medicine, Zhongshan Hospital, Fudan University,

Shanghai Medical College, Shanghai, China

Full list of author information is available at the end of the article
}

protein, quantitative protein and organelle [8]. Localizations, post-translational modifications, interactions, or turnovers of proteins produced by lymphocytes are summarized in Table 1. The present review overviewed the proteomicsbased studies on lymphocytes to headlight the proteomic profiles of lymphocytes in diseases, such as autoimmune diseases, allergic inflammation and cancer, with a special focus on lung diseases. We will explore the potential significance of diagnostic biomarkers and therapeutic targets from the current status in proteomic studies of lymphocytes and discuss the value of the currently available proteomic methodologies in the lymphocytes research.

\section{Autoimmune diseases}

The production of auto-antibodies from T- and B- lymphocytes were associated with lymphocyte-mediated immune responses [9]. Forty-two proteins were differentially expressed in human $\mathrm{CD} 4^{+} \mathrm{T}$ cells during the differentiation of naivve $\mathrm{CD} 4^{+} \mathrm{T}$ cells into Th1 cells induced by interleukin (IL)-12, of which 22 and 20 were up- and down- regulated respectively [10], as shown in Table 2 . In this particular study, macrophage migration inhibitory factor and programmed cell death 4 involved in cell rescue, defense, death and ageing were up-regulated. Macrophage migration inhibitory factor contributes to pro-inflammatory, 
Table 1 Categories of study design and techniques in lymphocyte proteomics

\begin{tabular}{|c|c|c|c|c|c|}
\hline Ref. & Disease/Activity & $\begin{array}{l}\text { Total identified } \\
\text { proteins }\end{array}$ & Samples & Country & Proteomic methods \\
\hline \multirow[t]{2}{*}{10} & \multirow{2}{*}{$\begin{array}{l}\text { IL-12 regulated CD4+ } \mathrm{T} \text { cells } \\
\text { differentiation }\end{array}$} & \multirow[t]{2}{*}{42} & \multirow[t]{2}{*}{ Blood } & \multirow[t]{2}{*}{ Finland } & $2-\mathrm{DE}$ \\
\hline & & & & & MS \\
\hline \multirow[t]{2}{*}{13} & \multirow[t]{2}{*}{ T cell proliferation } & \multirow[t]{2}{*}{17} & \multirow[t]{2}{*}{ Blood } & \multirow{2}{*}{$\begin{array}{l}\text { Hong Kong, } \\
\text { China }\end{array}$} & 2-DE \\
\hline & & & & & MALDI-TOF MS \\
\hline \multirow[t]{2}{*}{23} & \multirow[t]{2}{*}{ Mucosal tolerance } & \multirow[t]{2}{*}{11} & \multirow[t]{2}{*}{ Lymph node } & \multirow[t]{2}{*}{ Netherlands } & 2D-PAGE \\
\hline & & & & & MALDI-TOF MS \\
\hline \multirow[t]{2}{*}{27} & \multirow[t]{2}{*}{ T-cell vaccination (TCV) } & \multirow[t]{2}{*}{11} & \multirow{2}{*}{$\begin{array}{l}\text { Activated mouse } \\
\text { ovalbumin-specific T cells }\end{array}$} & \multirow[t]{2}{*}{ P. R. China } & 2-DE \\
\hline & & & & & Q-TOF MS \\
\hline 28 & Vogt-Koyanagi-Harada (VKH) syndrome & 30 & Blood & United States of America & LC-MS/MS \\
\hline \multirow[t]{2}{*}{29} & \multirow[t]{2}{*}{ Rheumatic heart disease (RHD) } & \multirow[t]{2}{*}{3} & Blood & \multirow[t]{2}{*}{ Brazil } & 2-DE \\
\hline & & & Cardiac tissue & & MALDI-TOF MS \\
\hline 32 & Tyrosine phosphorylation & 3 & $\begin{array}{l}\text { Primary human } \\
\text { lymphocyte }\end{array}$ & United States of America & 2D-PAGE \\
\hline 37 & Immunosuppression & 10 & E6-1 cell line & Spain & 2D-PAGE \\
\hline \multirow[t]{2}{*}{38} & \multirow[t]{2}{*}{ Colitis } & \multirow[t]{2}{*}{26} & \multirow[t]{2}{*}{ Lymph node } & \multirow[t]{2}{*}{ P. R. China } & 2D-PAGE \\
\hline & & & & & MS \\
\hline \multirow[t]{2}{*}{45} & \multirow[t]{2}{*}{ Pseudomonas aeruginosa sepsis } & \multirow[t]{2}{*}{11} & \multirow[t]{2}{*}{ Blood } & \multirow[t]{2}{*}{ P. R. China } & 2-DE \\
\hline & & & & & MALDI-TOF MS \\
\hline 46 & $\begin{array}{l}\text { DNA repair capacity (cell-cycle } \\
\text { checkpoint-related protein) }\end{array}$ & 8 & Blood & United States of America & $\begin{array}{l}\text { Reverse-phase protein } \\
\text { lysate microarray assay }\end{array}$ \\
\hline \multirow[t]{2}{*}{49} & Asthma & 25 & Blood & South Korea & 2D-PAGE \\
\hline & & & & & MALDI-TOF MS \\
\hline 50 & Asthma & 13 & Blood & Taiwan, China & 2D-PAGE \\
\hline & & & & & LC/MS \\
\hline
\end{tabular}

anti-inflammatory and oxidoreductase activities, while its polymorphisms were associated with $\mathrm{T}$ helper cell-related disorders $[11,12]$. Down-regulation of p21-activated kinase 2, GTPase Cdc42, and a heat shock family member mortalin 2 may promote lymphocyte survival and protection from programmed cell death.

Proteins involved in the $\mathrm{T}$ cell proliferation were defined during the suppression of PHA-treated T cells isolated from healthy donors, of which 13 proteins, e.g. peroxiredoxin-1, proteasomes and triosephospohate isomerase increased, while 4 like galectin-1 and Chain A reduced [13], as listed in Table 2. The identified differentially expressed proteins in lymphocytes were mainly involved in energy metabolism [14], anti-inflammatory pathways [15], oxidative stress [16] and protein breakdown [17], while a few were related to immune cell migration [18] and molecular chaperone [19]. T cell activation was inhibited by special inhibitors, e.g. cyclosporine A, polysaccharopeptide, or medical fungal products, through the alteration of proteins associated with the cell proliferation, including proteasomes, triosephospohate isomerase, galectin-1, Chain A, or perxiredoxin-1, respectively. Most of the altered proteins have functional significance in protein degradation [20], antioxidant pathway, energy metabolism [21], and immune cell regulation [22].

The intranasal delivery of auto-antigen could effectively induce mucosal tolerance and suppression of autoimmune diseases. Proteomic profiles of cervical lymph nodes were investigated to identify markers of the tolerant state 24,48 and $72 \mathrm{~h}$ after nasal administration of antigen [23]. Of them, haptoglobin, nonintegrin $67 \mathrm{kDa}$ laminin receptor (also known as P40-8), or Calgranulin A (MRP8) were related to the tolerance of immune through altering migration/mobility of antigen presenting cells and/or $\mathrm{T}$ cells [24,25] and anti-inflammatory activities [26]. The application of irradiated $\mathrm{T}$ cells as $\mathrm{T}$-cell vaccination showed preventive effects and experimental treatment in autoimmune diseases, through induction and production of anti-lymphocytic antibodies and inhibition of T-cell proliferation.

Proteomics is used not only for the identification and validation of biomarkers, but also for the characterization of the antigen specificity. Eleven antigens were identified in mouse $\mathrm{T}$ cells activated by ovalbumin and recognized by anti-T cell antibodies after the animals were immunized with ovalbumin-specific T cells, of which damage- 
Table 2 Dominant proteins associated with $\mathrm{T}$ cell activities

\begin{tabular}{|c|c|c|c|c|}
\hline Ref. & Activity & Protein & Expression & Functions \\
\hline \multirow[t]{5}{*}{10} & \multirow[t]{5}{*}{$\mathrm{T}$ cell differentiation } & Macrophage migration inhibitory factor (MIF) & Up-regulated & Cell resque, defense, death, ageing \\
\hline & & Programmed cell death $4(\mathrm{pdcd} 4)$ & Up-regulated & Cell resque, defense, death, ageing \\
\hline & & p21-activated kinase 2 (Pak2) & Down-regulated & Signal transduction \\
\hline & & Cdc42 & Down-regulated & Signal transduction \\
\hline & & Mortalin 2 (Mot-2) & Down-regulated & Protein destination \\
\hline \multirow[t]{4}{*}{13} & \multirow[t]{4}{*}{$\mathrm{T}$ cell proliferation } & Peroxiredoxin 1 & Up-regulated & A scavenger of reactive organic hydroperoxides \\
\hline & & Proteasomes & Up-regulated & $\begin{array}{l}\text { A large multisubunit proteolytic complex that } \\
\text { involved in an ATP/ubiquitin-dependent } \\
\text { non-lysosomal proteolytic pathway }\end{array}$ \\
\hline & & Triosephosphate isomerase (TIM) & Up-regulted & $\begin{array}{l}\text { Enzyme of metabolic pathways like converting } \\
\text { glyceraldehyde-3-phosphate to dehydroxyacetone } \\
\text { phosphate in the glycolytic pathway }\end{array}$ \\
\hline & & Galectin-1, Chain A & Down-regulated & $\begin{array}{l}\text { An anti-inflammatory agent which triggers } \\
\text { homeostatic signals to shut off T cell effector } \\
\text { functions such as cell proliferation, cell death and } \\
\text { cytokines synthesis, cell adhesion and } \\
\text { inflammation }\end{array}$ \\
\hline \multirow[t]{3}{*}{23} & \multirow[t]{3}{*}{ T cell supression } & Haptoglobin & Up-regulated & Anti-inflammatory activities \\
\hline & & Nonintegrin 67 kDa laminin receptor (LR) & Down-regulated & Lymphocyte migration \\
\hline & & MRP8 & Up-regulated & $\begin{array}{l}\text { Marker proteins for activated or recruited } \\
\text { phagocytes }\end{array}$ \\
\hline \multirow[t]{3}{*}{27} & \multirow[t]{3}{*}{ T cell activation } & Calreticulin (CRT) & \multirow[t]{3}{*}{ Identified } & \multirow{3}{*}{$\begin{array}{l}\text { Damage-associated molecular pattern molecules, } \\
\text { inducing immunogenic apoptosis }\end{array}$} \\
\hline & & Endoplasmic reticulum protein (ERp57) & & \\
\hline & & Vimentin & & \\
\hline
\end{tabular}

associated molecular pattern molecules were found to be dominant [27]. $\gamma$-radiation was found to induce the immunogenic apoptosis of activated T cells. Exposed/ secreted damage-associated molecular pattern molecules, e.g. calreticulin, endoplasmic reticulum protein 57 , and vementin, played an important role in T-cell vaccination therapy (Table 2).

$\mathrm{T}$ cells are considered as a major player in VogtKoyanagi-Harada (VKH) syndrome, an autoimmune disorder, which mainly affects systemic melanocytes in eyes, menings, ears, skin, or hairs. Membrane proteins in $\mathrm{CD}^{+} \mathrm{T}$ cells from patients with active VKH syndrome were analyzed with a label-free quantitative proteomic strategy to identify disease-associated proteins as compared with healthy individuals [28]. 102 significantly altered peptides were identified and corresponded to 64 proteins, of which 30 had 1.5-fold alterations, as summarized in Table 3. The expression of CD18 and AT-hook transcription factor decreased and then further validated in an additional group of patients with $\mathrm{VKH}$ syndrome, major players in the pathogenesis of the syndrome. Molecular mimicry between group A streptococcus antigens and host proteins was investigated in $\mathrm{B}$ and $\mathrm{T}$ cells from patients with rheumatic heart disease with the major manifestation of rheumatic fever due to streptococcus pharyngitis. Three proteins in heart infiltrating and peripheral $\mathrm{T}$ cells isolated from the valvular tissue from patients with chronic rheumatic heart disease were identified as T cell-targeted proteins, e.g. disulfide isomerase ER-60 precursor, $78 \mathrm{kD}$ glucose-regulated protein precursor, and vimentin, with coverage of 45,43 , and $34 \%$, respectively [29]. They were believed similar to antigens involved in $\mathrm{T}$ cell-mediated autoimmune responses in rheumatic fever/rheumatic heart diseases.

\section{Allergic inflammation}

Lymphocytes and their products, together with other leukocytes, contribute to the initiation and perpetuation of the inflammatory response, through the alterations of protein profiles [30]. Protein tyrosine phosphorylation was suggested to play a critical role in regulation of gene transcription, cell proliferation, differentiation, cytoskeletal organization, and survival in lymphocytes during the development of tissue remodeling in chronic inflammation induced by allergen [31]. Protein profiles associated with tyrosine phosphorylation were investigated in Daudi, Burkitt's lymphoma-derived B cell lines, and BJAB, B cell lymphoma-derived B cell lines, using a battery of Src homology 2 domain probes, and similar patterns of tyrosine phosphorylation for the Fyn and phosphatidylinositol-3kinase Src homology 2 were found but not in Crk Src homology 2 [32]. The fingerprinting of proteins associated 


\begin{tabular}{|c|c|c|c|}
\hline Identified proteins & Expression & Number of peptides & Function \\
\hline Integrin $\beta$ & Up-regulated & Singe & Protein binding \\
\hline Coronin-2A & Up-regulated & Singe & Protein binding \\
\hline C19orf2 protein & Up-regulated & Singe & Protein binding \\
\hline Isoform 4 of Dystrophin & Up-regulated & Singe & $\begin{array}{l}\text { Structural constitute of cytoskeleton, muscle; } \\
\text { protein, calcium ion, actin, zinc ion binding }\end{array}$ \\
\hline Synaptonemal complex protein 2 & Up-regulated & Singe & DNA binding \\
\hline Hypothetical protein LOC345651 & Up-regulated & Singe & Protein binding \\
\hline $\begin{array}{l}\text { Isoform } 1 \text { of Solute carrier family } 22 \\
\text { member } 11\end{array}$ & Up-regulated & Singe & $\begin{array}{l}\text { Sodium-independent organic anion } \\
\text { transporter activity }\end{array}$ \\
\hline $\begin{array}{l}\text { UBC; UBB ubiquitin and ribosomal protein } \\
\text { S27a precursor }\end{array}$ & Up-regulated & Singe & Structural constituent of ribosome \\
\hline PRA1 family protein 3 & Up-regulated & Singe & Protein binding \\
\hline Actin, cytoplasmic 1 & Up-regulated & Singe & $\begin{array}{l}\text { Structural constituent of cytoskeleton; protein, } \\
\text { ATP, nucleotide binding }\end{array}$ \\
\hline $\begin{array}{l}\text { Probable G-protein coupled receptor } 179 \\
\text { precursor }\end{array}$ & Up-regulated & Singe & $\begin{array}{l}\text { Metabotropic glutamate, GABA-B-like receptor } \\
\text { activity }\end{array}$ \\
\hline $\begin{array}{l}\text { Heat shock } 70 \mathrm{kDa} \text { protein 9, mitochondrial } \\
\text { precursor }\end{array}$ & Up-regulated & Singe & $\begin{array}{l}\text { Unfolded protein binding; ATP, nucleotide } \\
\text { binding }\end{array}$ \\
\hline ELMO2 protein & Up-regulated & Singe & Binding \\
\hline Isoform 1 of Peripherin & Down-regulated & Singe & Structural molecule activity \\
\hline $\begin{array}{l}\text { ATP synthase subunit } a \text {, mitochondrial } \\
\text { precursor }\end{array}$ & Down-regulated & Singe & $\begin{array}{l}\text { Protein, ATP, nucleotide, metal ion binding; } \\
\text { hydrogen-transporting ATPase/ATP synthase } \\
\text { activity; hydrolase, transporter activity }\end{array}$ \\
\hline Calnexin precursor & Down-regulated & Singe & $\begin{array}{l}\text { Calcium ion, sugar binding; unfolded protein } \\
\text { binding }\end{array}$ \\
\hline Integrin $\beta-2$ precursor & Down-regulated & Singe & $\begin{array}{l}\text { Protein, protein kinase binding; receptor } \\
\text { activity }\end{array}$ \\
\hline Vimentin & Up-regulated & Two or more & $\begin{array}{l}\text { Structural constituent of cytoskeleton; protein } \\
\text { binding; structural molecule activity; oxygen } \\
\text { transporter activity }\end{array}$ \\
\hline Keratin, type I cytoskeletal 10 & Up-regulated & Two or more & $\begin{array}{l}\text { Structural constituent of epidermis; structural } \\
\text { molecule activity }\end{array}$ \\
\hline $\begin{array}{l}\text { ATP synthase subunit } \beta \text {, mitochondrial } \\
\text { precursor }\end{array}$ & Up-regulated & Two or more & $\begin{array}{l}\text { Protein, ATP, nucleotide, metal ion binding; } \\
\text { hydrogen-transporting ATPase/ATP synthase } \\
\text { activity; hydrolase, transporter activity; } \\
\text { hydrogen-exporting ATPase activity; } \\
\text { nucleotide-triphosphatase activity }\end{array}$ \\
\hline Actin, aortic smooth muscle & Up-regulated & Two or more & $\begin{array}{l}\text { Structural constituent of cytoskeleton; protein, } \\
\text { ATP, nucleotide binding }\end{array}$ \\
\hline Keratin, type II cytoskeletal 1 & Up-regulated & Two or more & $\begin{array}{l}\text { Structural constituent of cytoskeleton; protein, } \\
\text { sugar binding; receptor activity }\end{array}$ \\
\hline Uncharacterized protein ALB & Up-regulated & Two or more & $\begin{array}{l}\text { Protein, water, toxin, pyridoxal phosphate, } \\
\text { drug, fatty acid, oxygen, copper ion, DNA, } \\
\text { metal ion binding; carrier, antioxidant activity }\end{array}$ \\
\hline $\begin{array}{l}\text { Isoform ASF-1 of Splicing factor, } \\
\text { arginine/serine-rich } 1\end{array}$ & Down-regulated & Two or more & Protein, nucleotide, RNA binding \\
\hline
\end{tabular}

with signal transduction pathways in response to IL-2 or interferon (IFN)- $\gamma$ in human lymphocytes demonstrated that IFN- $\gamma$ could induce STAT2 phosphorylation, IL-2activated phosphatidylinositol-3-kinase phosphoprotein, or both, involved in phosphorylation of transcription factor
Jak-1 by anti-phosphotyrosine immunoprecipitations and proteomic analysis [33]. Chromatin-associated regulatory factors play central roles in the regulation of cell proliferation, differentiation, senescence, and death in lymphocyte. Proteomic analysis of chromatin-associated proteins 
demonstrated that transcription and replication factors varied in human B cells (P493-6 cells) expressing c-Myc in a tetracycline-repressible manner [34].

Proteomic profiles in lymphocytes were analyzed under challenges with concanavalin A-stimulated mouse spleen cells cultured with or without cyclosporine A and restimulated in the presence or absence of concanavalin A, to monitor the response of protein profiles to immunosuppressions and activations [35]. Cyclosporine A was found to activate and program the transcription and translation of a large number of genes in $T$ cells without further reactivation, once the immunosupressor and the activator were removed. Cyclosporine A could induce down-regulation of immune responses through the calcineurin-dependent dephosphorylation of nuclear factors in activated $\mathrm{T}$ cells, which was interfered by new and specific synthesized polypeptides without affecting the expression of CD44 and CD69 and early tyrosine phosphorylation-associated protein profiles [36]. Of 111 protein spots altered in human $\mathrm{T}$ cells cultured with the potent immunosuppressant rapamycin, 70 increased and 41 decreased, of which annexin $\mathrm{V}$ and Ro/SSA antigen increased and $\alpha$-enolase and laminin receptor 1 decreased [37].

There is increasing evidence to show that altered proteomic profiles of lymphocytes could dominate the development of allergic inflammation. For example, altered protein profiles of lymphocytes were investigated in an antigen-specific model of colitis induced by colonic administration of trinitrobenzene sulfonic acid/ethanol [38]. Of 1,100 protein spots, 26 proteins had more than at least two-fold differences between colitis and control, among which 17 up-regulated and 9 down-regulated, including CARD and PYD domain containing protein, proteasome activator complex subunit 2, IL-12 p40 precursor, nucleoside diphosphate kinase, ubiquitin-conjugating enzyme E2N, myeloid-related protein-14, ATP-citrate synthase, phosphoglycerate mutase and dismutase. The altered proteins served as regulators of the cell cycle and cell proliferation [39], signal transduction factors [40,41], inflammatory factors [42], apoptosis-related proteins [43,44] and metabolic enzymes, as illustrated in Figure 1. Alterations of protein profiles in lymphocytes in allergic diseases differed from those in serious diseases and bacterial infection [45]. Altered protein profiles in severe burn and Pseudomonas aeruginosa sepsis were found to be associated with the folding, assembling, transportation and degradation of proteins, signal transmission, inflammation, immunization, energy metabolism, the proliferation, differentiation and apoptosis of cells, including Cofilin, peptidyl-prolyl cis-trans isomerase cyclophilin A, ubiquitin, nucleoside diphosphate kinase, glutamate dehydrogenase, selenium binding protein I, beta-actin, peroxiredoxin- 6 , annexin I, actin-3 and cellular retinoic-acid binding protein.

\section{Cancer}

The innate DNA repair capacity (DRC) is the central in controlling multistage carcinogenesis, and suboptimal DRC in peripheral lymphocytes was suggested as a cancer susceptibility marker and a functional link between DNA damage sensing, cell-cycle checkpoint, and DNA

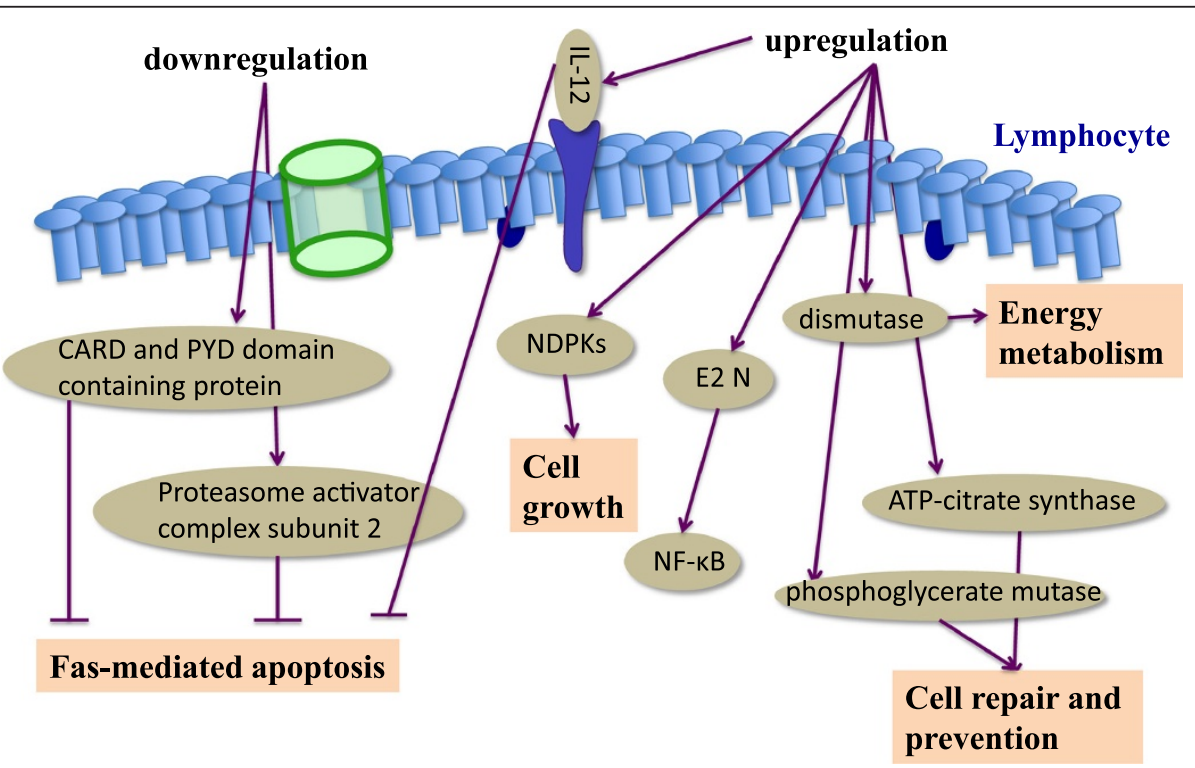

Figure 1 Altered protein profile of lymphocytes from rats with colitis. The altered proteins of lymphocytes in colitis fell into the following groups: apoptosis-related proteins, proteins associated with cell growth, differentiation and signal transduction, inflammation factors, proteins associated with metabolism and oxidative stress response. IL-12, interleukin-12; NDPKs, nucleoside diphosphate kinases; E2 N, ubiquitin-conjugating enzyme; NF-kB, nuclear factor $\mathrm{kB}$. 
repair. Levels of in vitro cell-cycle checkpoint-related protein expressions in stimulated lymphocytes could predict DRC levels. The host-cell reactivation assay and the reverse-phase protein lysate microarray assay demonstrated that the DRC was significantly correlated with expression levels of cell-cycle checkpoint-related proteins, e.g. cyclin dependent kinase inhibitor (p27), cell cycle regulator (cyclin D1), DNA damage sensor (ataxia-telangiectasia mutated), and p53-negative regulator (mouse double minute 2 homo$\log$ ), induced by benzo[a]pyrene diol epoxide-adducts [46]. Ataxia-telangiectasia mutated was identified as the most important predictor of DRC, followed by mouse double minute 2 homolog and $\mathrm{p} 27$, a population-based in vitro evidence that cell-cycle checkpoint-related proteins may play essential roles in the regulation of DNA repair in unaffected human peripheral blood lymphocytes. $\mathrm{CD}^{+} \mathrm{T}$ cells are considered as the major players in immune responses against cancer, with the cytotoxic activity and capability to release various mediators. Studies on network and functional characterization of proteins specific to resting or activated human $\mathrm{CD}^{+} \mathrm{T}$ cells provide new insight into the signaling pathway of $\mathrm{CD}^{+} \mathrm{T}$ cell activation with anti-CD3 and anti-CD28 mAb in the presence of IL-2 [47]. The altered expression of 35 proteins were mainly related with cell proliferation, metabolic pathways, antigen presentation, intracellular signal transduction pathways, as well as identification of six unknown proteins and predicted from genomic DNA sequences specific to resting or activated $\mathrm{CD}^{+}$ T cells.

\section{Lung diseases}

\section{Asthma}

Asthma is a complex disorder characterized by airway inflammation, goblet cell hyperplasia with mucus hypersecretion, and hypersponsiveness to various nonspecific stimuli. $\mathrm{CD}^{+} \mathrm{T}$ lymphocytes, especially Th2 lymphocytes, play an important role in the initiation, progression and persistence of asthma [48]. The expression of 13 proteins increased and 12 decreased in $\mathrm{T}$ lymphocytes from asthmatic patients, as compared to the healthy [49]. Among them, phosphodiesterase $4 \mathrm{C}$, heat shock protein (HSP)-70, protein tyrosine phosphatase, $\beta$-arrestin- $1 \mathrm{~b}$, thioredoxin-like 2 , LLR protein, glutathione reductase, major histocompatibility complex class I antigen, epidermal growth factor receptor, pyrroline 5-carboxylate reductase isoform, and FLJ25770 protein increased, while dynein, cytoplasmic light intermediate polypeptide 2 , vimentin, zinc finger protein 76 , tubulin $\beta_{2}$, T-cell receptor $\beta$-chain, cyclindependent kinase 6 , pyridoxal kinase, phenylalanine hydroxylase, glutathione S-transferase-M3, and tetratricopeptide repeat-containing protein decreased. Of identified proteins, increased mRNA expression of phosphodiesterase $4 \mathrm{C}$ and thioredoxin- 2 and decreased mRNA of glutathione S-transferase-M3 were further confirmed by
RT-PCR in the large population of asthmatic patients. Figure 2 demonstrates some of the identified proteins and their role in asthma. To investigate the changes of proteins in $\mathrm{T}$ lymphocytes of asthmatic patients after no typical therapy (uncontrolled) to typical therapy (controlled) over 3 months, 7 proteins increased and 6 decreased in $\mathrm{CD}^{+} \mathrm{T}$ lymphocytes from uncontrolled asthmatic patients, including HSP-70, HSP-90, fibrinogen $\beta$ chain, tropomyosin 3 , ATP-dependent DNA helicase II, $\beta$-actin, vimentin, Rho GDP dissociation inhibitor beta, enolase 1, calreticulin precursor, tyrosine 3-monooxygenase/ tryptophan 5-monooxygenase activation protein (YWHA), or peroxiredoxin 2, as compared to those from controls [50]. Two studies showed that HSP-70 increased and vimentin decreased in asthmatics and uncontrolled asthmatics. HSP is a ubiquitous, abundant, and conserved protein and synthetic rate of HSP increased in response to cellular stress, to protect the cells and tissues from the deleterious effects of numerous mediators, reactive oxygen species, or tumor necrosis factor- $\alpha$. Other studies suggested that HSP is correlated with the severity of asthma exacerbation [51,52]. Vimentin, as a kind of cytoskeletal proteins and a type III intermediate filament protein normally expressed in cells of mesenchymal origin, attaches to the nucleus, endoplasmic reticulum, and mitochondria to control the shape, motility, and migration of mesenchymal cells [53]. The cytoskeletal changes in $\mathrm{T}$ lymphocytes of asthma patient may contribute to enhanced activity of proinflammatory and immune cells, reduced antioxidant defenses, functional changes in the $\mathrm{T}$ lymphocyte of asthma patient, or abnormal repair process responsible for airway inflammation and remodeling during damage to the epithelium. Such panel of altered proteins associated with the pathogenesis of asthma could be potential biomarkers and therapeutic targets in asthma.

\section{Idiopathic Pulmonary Fibrosis (IPF)}

IPF is a devastating disease characterized by a progressive distortion of the alveolar architecture and replacement by fibrotic tissue and extracellular matrix deposition. There are still no effective therapies for IPF which results in chronic respiratory failure and death associated with autoimmunity, though mechanism of autoimmunity involvement in the pathogenesis of IPF remains unclear. The expression of 51 proteins increased and 38 decreased in lungs of patients with sporadic IPF, as compared with healthy controls [54]. Up-regulated expression of markers for the unfolded protein response, HSP, and DNA damage stress markers indicated a chronic cell stress-response in IPF lungs. Down-regulated proteins in IPF included antioxidants, annexin family, and structural epithelial proteins, related with redox imbalance, epithelial cell injury, extensive fibrotic reaction, and increased susceptibility of IPF patients to infection. Proteomic analysis also identified for the first time the presence of anti-periplakin (PPL) 


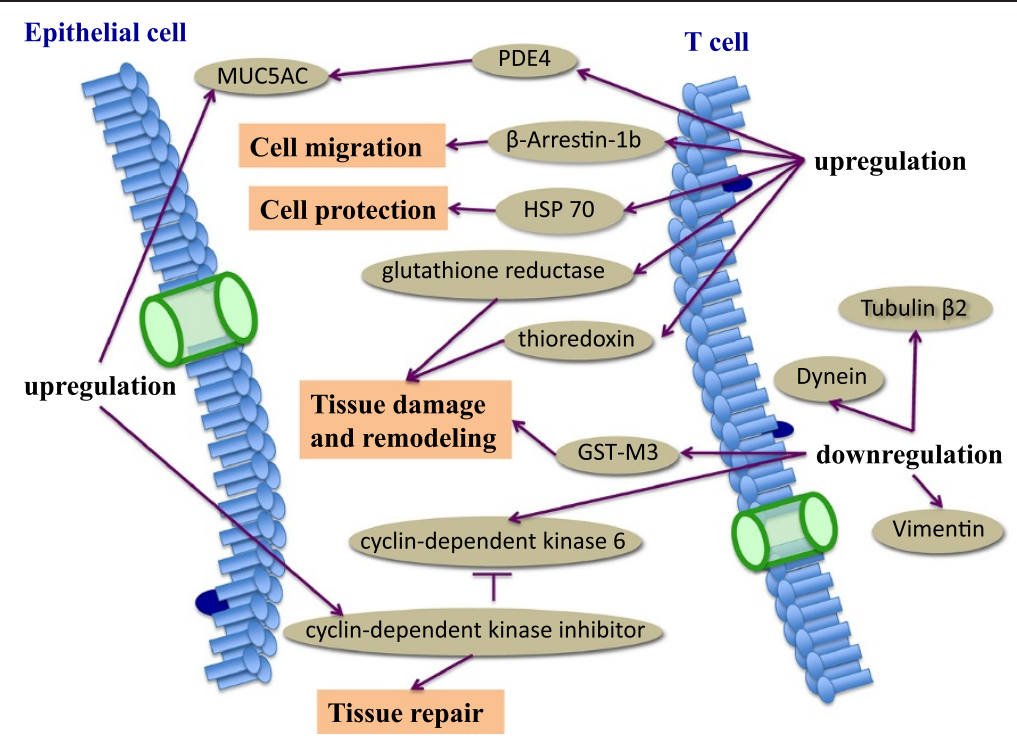

Figure 2 Altered protein profiles of T cells from asthma patients. PDE4, hydrolyzing cyclic adenosine monophosphate and/or cyclic guanosine monophosphate, was associated with the MUC5AC expression in human airway epithelial cells. $\beta$-Arrestin was suggested to play a role in T cell migration. Glutathione reductase, GST-M3 and thioredoxin were correlated with the antioxidant capacity. HSP-70 protects the cells and tissues from the deleterious effects of numerous mediators, reactive oxygen species, or tumor necrosis factor-a. Cytoskeletal proteins, including Dynein, Vimentin, Tubulin $\beta 2$, might illustrate the functional changes in the T cells. Cyclin-dependent kinase was related to an abnormal repair process that might contribute to airway inflammation and remodeling. PDE, phosphodiesterase; HSP, heat shock protein; GST, glutathione S transferase.

antibodies in serum and brochoalveolar lavage fluid in patients with IPF [55]. PPL is a small protein from the plakin family, closely related to envoplakin and localized to demosomes and intermediate filaments [56]. PPL is constitutively expressed in both bronchial and alveolar epithelia and the intracellular distribution of PPL is modified in the hyperplastic alveolar epithelium of fibrotic lungs. PPL interacts with intermediate filaments in the cell and is required for the reorganization of keratin intermediate filaments network at the wound edge of simple epithelia cell monolayers and for the correct closure of an experimental wound [57]. The C-terminal domain of PPL can be linked to several intracellular proteins, such as protein kinase B ATK1/PKB [58] or Fc $\gamma \mathrm{RI}$ [59], leading to changes in cellular functions. Anti-PPL antibodies have the potential to interfere with alveolar repair and are associated with the severity of the disease, indicating that the abnormal responses of autoimmune contribute directly to the pathogenesis of IPF.

\section{Lung cancer}

Lung cancer is the most common cause of cancer-related mortality in the world, resulting in an overall 5-year survival rate of approximately $15 \%$ [60]. Proteome components related to therapeutic responses and targeted proteins in lung cancer cells and tissues were identified to define potential biomarkers with diagnostic, prognostic, and predictive values or drug-targeted candidates. To achieve a difference in the management of lung cancer, short of preventing its development, it is important to diagnose it early while it is measurable yet presymptomatic. The development of specific and sensitive diagnostic biomarkers from biological fluids, such as sputum, blood, or exhaled breath, should improve early detection strategies, monitoring of disease progression, treatment response, and surveillance for recurrence.

\section{Proteomic methodologies}

Proteins are separated from cells and then subjected to complexity reduction, either via chromatographic or electrophoretic fractionation, or via enrichment of desired components, like membrane proteins, a particular sub-cellular component, or specific protein complex separation via affinity purification. Proteins can be identified via proteolysis and analysis of resultant peptides in mass spectrometer (MS), followed by database-searching. MS is an indispensable core of proteomic technologies and allows highly sensitive and high-throughput identification of proteins, post-translational modifications, or protein interaction [61,62]. Two-dimensional gel electrophoresis for separation of complex protein samples from blood, lymph nodes or cell lines, coupled with MS for protein identification, can analyze protein expression patterns for profiling lymphocyte proteomics, as shown in Table 1. A large variation of MS technologies is currently available, 
evolved from electrospray ionization and matrix-assisted laser desorption/ionization (MALDI) to a new generation of mass analyzers and complex multistage instruments [such as hybrid quadrupole time-of-flight (Q-TOF)] $[61,63]$. The MS technologies in lymphocyte proteomics include MALDI-TOF, MS/MS (tandem MS), or Q-TOF. MALDI-TOF-MS can identify a wide mass range (1$300 \mathrm{kDa}$ ) of proteins in lymphocytes with a high accuracy and sensitivity and analyse post-translational protein modifications [64]. In combination with others, MALDI-TOF-MS is particularly suitable for the identification of protein spots via mass fingerprint or microsequencing. Peptide mass fingerprinting (PMF) by MALDI-MS and sequencing by tandem MS have evolved into the major methods for identification of protein following separation by two-dimensional gel electrophoresis, sodium dodecyl sulfate polyacrylamide gel electrophoresis, or liquid chromatography. The PMF for protein identification is exemplified with high molecular masses, low molecular masses, splice variants, aggregates with disulfide bridges, and phosphorylated proteins [65]. It is necessary to quantitatively determine the changes of proteomes or sub-proteomes in responses to stimuli and to fully elucidate lymphocyte signaling mechanisms and function. Isotope-coded affinity tagging is one of the most employed chemical isotope labeling methods and the first quantitative proteomic method to be based solely on using MS [66,67], and has been applied to a wide range of biological systems, including lymphocyte signaling $[34,68]$. By labeling cysteine residues of proteins from two different sources with ${ }^{12} \mathrm{C}$ and ${ }^{13} \mathrm{C}$, respectively, isotope-coded affinity tagging allows comparison and relative quantitation of two or more bio-samples.

\section{Therapeutic significance}

Proteomic approaches can determine expressed proteins in lymphocytes and describe the interactions between proteins and targeted regulatory signaling networks. Lymphocytes are a central component of immune defense mechanisms against pathogens and novel therapeutic strategies towards diseases. Identified profiles of tyrosine phosphorylation [31], proliferation [13], cell activation [37], or chromatinassociated proteins [34] in lymphocytes can help to build a comprehensive view of therapeutic strategies for diseases. CD20 and CD23 are immune regulators as therapeutic targets for heamatological malignancies, autoimmune diseases and allergic disorders, and a new subset of palmitoylated proteins in B cells [69].

\section{Conclusions}

The understanding of lymphocyte profiles is one of the most critical approaches to investigate their functions and roles in the development of diseases. The proteomics- based studies on lymphocytes headlight the proteomic profiles of lymphocytes in diseases, such as autoimmune diseases, allergic inflammation and cancer, with a special focus on lung diseases. Proteomic studies of lymphocytes provide the potential significance of disease-specific diagnostic biomarkers and therapeutic targets. There is an urgent need of standard protocols to carry out proteomic studies on lymphocytes. The current achievements in profiling protein expression in lymphocytes will open the new window to develop therapeutic strategies and targets.

\section{Abbreviations \\ IL: Interleukin; VKH: Vogt-Koyanagi-Harada; IFN: Interferon; DRC: DNA repair capacity; HSP: Heat shock protein; IPF: Idiopathic pulmonary fibrosis; PPL: periplakin; MS: Mass spectrometry; MALDI: Matrix-assisted laser desorption/ionization; Q-TOF: Quadrupole time-of-flight; PMF: Peptide mass fingerprinting.}

\section{Competing interest}

The authors declare that they have no competing interests.

\section{Authors' contributions}

JBZ and ZTZ contributed to collection of information, analysis and interpretation of data and writing of the manuscript. CXB contributed to revision of the manuscript. HZS and XDW contributed to design and revision of the manuscript. All authors read and approved the final manuscript.

\section{Acknowledgements}

The work was supported by Shanghai Leading Academic Discipline Project (Project Number: B115), Zhongshan Distinguished Professor Grant (XDW), The National Nature Science Foundation of China (91230204, 81270099, $81320108001,81270131)$, The Shanghai Committee of Science and Technology (12JC1402200, 12431900207, 11410708600), Zhejiang Provincial Natural Science Foundation (Z2080988), Zhejiang Provincial Science Technology Department Foundation (2010C14011), and Ministry of Education, Academic Special Science and Research Foundation for PhD Education (20130071110043)

\section{Author details}

'Department of Pulmonary Medicine, Zhongshan Hospital, Fudan University, Shanghai Medical College, Shanghai, China. ${ }^{2}$ Shanghai Respiratory Research Institute, Shanghai, China. ${ }^{3}$ Center for Cancer Molecular and Cellular Therapies, The First Affiliated Hospital of Liaoning Medical University, Liaoning, China.

Received: 21 November 2013 Accepted: 4 January 2014 Published: 7 January 2014

\section{References}

1. von Andrian UH, Mackay CR: Advances in immunology: T-cell function and migration - Two sides of the same coin. N Engl J Med 2000, 343:1020-1033.

2. Delves P, Roitt IM: The immune system - First of two parts. N Engl J Med 2000, 343:37-49.

3. Delves $P$, Roitt IM: Advances in immunology: the immune system - second of two parts. N Engl J Med 2000, 343:108-117.

4. Pabst $R$, Tschernig T: Lymphocytes in the lung: an often neglected cells. Numbers, characterization and compartmentalization. Anat Embryol (Berl) 1995, 192:293-299.

5. Baumgartner C, Osl M, Netzer M, Baumgartner D: Bioinformatic-driven search for metabolic biomarkers in disease. J Clin Bioinforma 2011, 1:2.

6. Wang XD, Liotta L: Clinical bioinformatics: a new emerging science. J Clin Bioinforma 2011, 1:1.

7. Abraham E, Marincola FM, Chen ZN, Wang XD: Clinical and translational medicine: integrative and practical science. Clin Trans/ Med 2012, 1:1.

8. Wollscheid B, Watts JD, Aebersold R: Proteomics/genomics and signaling in lymphocytes. Curr Opin Immunol 2004, 16:337-344. 
9. van Mühlen CA, Tan EM: Autoantibodies in the diagnosis of systemic rheumatic diseases. Semin Arthritis Rheum 1995, 24:333-358.

10. Rosengren AT, Nyman TA, Lahesmaa R: Proteome profiling of interleukin-12 treated human T helper cells. Proteomics 2005, 5:3137-3141.

11. Baugh JA, Chitnis S, Donnelly SC, Monteiro J, Lin X, Plant BJ, Wolfe F, Gregersen PK, Bucala R: A functional promoter polymorphism in the macrophage migration inhibitory factor (MIF) gene associated with disease severity in rheumatoid arthritis. Genes Immun 2002, 3:170-176.

12. Donn R, Alourfi Z, De Benedetti F, Meazza C, Zeggini E, Lunt M, Stevens A, Shelley E, Lamb R, Ollier WE, Thomson W, Ray D: Mutation screening of the macrophage migration inhibitory factor gene: positive association of a functional polymorphism of macrophage migration inhibitory factor with juvenile idiopathic arthritis. Arthritis Rheum 2002, 46:2402-2409.

13. Lee $\mathrm{CL}$, Jiang PP, Sit WH, Wan JMF: Proteome of human T lymphocytes with treatment of cyclosporine and polysaccharopeptide: Analysis of significant proteins that manipulate T cells proliferation and immunosuppression. Int Immunopharmacol 2007, 7:1311-1324.

14. Ationu A, Humphries A: The feasibility of replacement therapy for inherited disorder of glycolysis: triosephosphate isomerase deficiency. Int J Mol Med 1998, 2:701-704.

15. Rabinovich GA, Alonso CR, Sotomayor CE, Durand S, Bocco JL, Riera CM: Molecular mechanisms implicated in galectin-1-induced apoptosis: activation of the AP-1 transcription factor and downregulation of $\mathrm{Bcl}-2$. Cell Death Differ 2000, 7:747-753.

16. Bryk R, Griffin P, Nathan C: Peroxynitrite reductase activity of bacterial peroxiredoxins. Nature 2000, 407:211-215.

17. Tanaka K, Chiba T: The proteasome: a protein-destroying machine. Genes Cells 1998, 3:499-510.

18. Sousa LP, Silva BM, Brasil BS, Nogueira SV, Ferreira PC, Kroon EG, Kato K, Bonjardim CA: Plasminogen/plasmin regulates alpha-enolase expression through the MEK/ERK pathway. Biochem Biophys Res Commun 2005, 337:1065-1071.

19. Anderson RL, Fong KJ, Gabriele T, Lavagnini P, Hahn GM, Evans JW, Waldren CA, Stamato TD, Giaccia AJ: Loss of the intrinsic heat resistance of human cells and changes in $\mathrm{Mr} 70,000$ heat shock protein expression in human $\times$ hamster hybrids. J Cancer Res 1991, 51:2636-2641.

20. Rolfe M, Chiu Ml, Pagano M: The ubiquitin-mediated proteolytic pathway as a therapeutic area. J Mol Med 1997, 75:5-17.

21. Wierenga RK, Borchert TV, Noble ME: Crystallographic binding studies with triosephosphate isomerases: conformational changes induced by substrate and substrate-analogues. FEBS Lett 1992, 307:34-39.

22. Rabinovich GA, Baum LG, Tinari N, Paganelli R, Natoli C, Liu FT, Lacobelli S: Galectins and their ligands: amplifiers, silencers or turners of the inflammatory response? Trends Immunol 2002, 23:313-320.

23. Boots AM, Verhaert PD, Poele RJT, Evers S, Coenen-de Roo CJ, Cleven J, Bos ES: Antigens up the nose: identification of putative biomarkers for nasal tolerance induction functional studies combined with proteomics. J Proteome Res 2004, 3:1056-1062.

24. Kerkhoff $C$, Klempt M, Sorg C: Novel insights into structure and function of MRP8 (S100A8) and MRP14 (S100A9). Biochim Biophys Acta 1998, 1448:200-211.

25. Canfield SM, Khakoo AY: The nonintegrin laminin binding protein (p67 LBP) is expressed on a subset of activated human T lymphocytes and, together with the integrin very late activation antigen-6, mediates avid cellular adherence to laminin. J Immunol 1999, 163:3430-3440.

26. Dobryszycka W: Biological functions of haptoglobin-new pieces to an old puzzle. Eur J Clin Chem Clin Biochem 1997, 35:647-654.

27. $\mathrm{Xu} \mathrm{W}$, Li XQ: Immunoproteomic analysis of the antibody response obtained in mouse following vaccination with a T-cell vaccine. Proteomics 2011, 11:4368-4375

28. Mao LM, Yang PZ, Hou SP, Li FZ, Kijlstra A: Lable-free proteomics reveals decreased expression of CD18 and AKNA in peripheral CD4(+) T cells from patients with Vogt-Koyanagi-Harada syndrome. Plos One 2011, 6:e14616.

29. Fae KC, da Silva DD, Bilate AMB, Tanaka AC, Pomerantzeff PMA, Kiss MH, Silva CAA, Cunha-Neto E, Kalil J, Guilherme L: PDIA3, HAPA5 and viementin, proteins identified by $2-D E$ in the valvular tissue, are the target antigens of peripheral and heart infiltrating $T$ cells from chronic rheumatic heart disease patients. J Autoimmun 2008, 31:136-141.
30. Wang XD, Zhao $H$, Avdersson R: Proteomics and leukocytes: an approach to understanding potential molecular mechanisms of inflammatory responses. J Proteome Res 2004, 3:921-929.

31. Komai M, Tanaka H, Masuda T, Nagao K, Ishizaki M, Sawada M, Nagai H: Role of Th2 responses in the development of allergen-induced airway remodelling in a murine model of allergic asthma. Br J Pharmacol 2003, 138:912-920.

32. Nollau P, Mayer BJ: Profiling the global tyrosine phosphorylation state by Src homology 2 domain binding. Proc Natl Acad Sci USA 2001, 98:13531-13536.

33. Stancato LF, Petricoin EF 3rd: Fingerprinting of signal transduction pathways using a combination of anti-phosphotyrosine immunoprecipitations and two-dimensional polycrylamide gel electrophoresis. Electrophoresis 2001, 22:2120-2124

34. Shiio Y, Eisenman RN, Yi EC, Donohoe S, Goodlett DR, Aebersold R: Quantitative proteomic analysis of chromatin-associated factors. J Am Soc Mass Spectrom 2003, 14:696-703.

35. Truffa-Bachi P, Lefkovits I, Frey JR: Proteomic analysis of T cell activation in the presence of cyclosporin A: immunosuppressor and activator removal induces de novo protein synthesis. Mol Immunol 2000, 37:21-28.

36. Mascarell L, Frey JR, Michel F, Lefkovits I, Truffa-Bachi P: Increased protein synthesis after $\mathrm{T}$ cell activation in the presence of cyclosporin A. Transplantation 2000, 70:340-348.

37. Grolleau A, Bowman J, Pradet-Balade B, Puravs E, Hanash S, Garcia-Sanz JA, Beretta L: Global and specific translational control by rapamycin in T cells uncovered by microarrays and proteomics. J Biol Chem 2002, 277:22175-22184.

38. Liu BG, Cao YB, Cao YY, Zhang JD, An MM, Wang Y, Gao PH, Yan L, Xu Y, Jiang $Y Y$ : Altered protein profile of lymphocytes in an antigen-specific model of colitis: a comparative proteomic study. Inflamm Res 2007, 56:377-384

39. Kimura N, Shimada N, Fukuda M, Ishijima Y, Miyazaki H, Ishii A, Takagi Y, Ishikawa N: Regulation of cellular functions by nucleoside diphosphate kinase in mammals. J Bioenerg Biomembr 2000, 32:309-315.

40. Firestein $\mathrm{R}$, Feuerstein $\mathrm{N}$ : Association of activating transcription factor 2 (ATF2) with the ubiquitin-conjugating enzyme hUBC9. Implication of the ubiquitin/proteasome pathway in regulation of ATF2 in T cells. J Biol Chem 1998, 273:5892-5902.

41. Orian A, Whiteside S, Israel A, Stancovski I, Schwartz AL, Ciechanover A: Ubiquitin-mediated processing of NF-kappa B transcriptional activator precursor p105. Reconstitution of a cell-free system and identification of the ubiquitin-protein ligase, E3, involved in conjugation. J Biol Chem 1995, 270:21707-21714.

42. Lominadze G, Rane MJ, Merchant M, Ca J, Ward RA, McLeish KR: Myeloidrelated protein-14 is a p38 MAPK substrate in human neutrophils. $J$ Immunol 2005, 174:7257-7267.

43. Shiohara M, Taniguchi S, Masumoto J, Yasui K, Koike K, Komiyama A, Sagara $\mathrm{J}$ : ASC, which is composed of a PYD and a CARD, is up-regulated by inflammation and apoptosis in human neutrophils. Biochem Biophys Res Commun 2002, 293:1314-1318.

44. Tanimoto Y, Kizaki H: Proteasome inhibitors block Ras/ERK signaling pathway resulting in the downregulation of Fas ligand expression during activation-induced cell death in T cells. J Biochem 2002, 131:319-326.

45. Zheng JZ, Zhang PH, Li LL, Ren LC, Liang PF, Huang XY: Proteomic study of peripheral blood lymphocytes of rabbits with severe burn and Pseudomonas aeruginosa sepsis. Zhongguo Wei Zhong Bing Ji Jiu Yi Xue 2009, 21:455-459.

46. Fan YH, Hu ZB, Li CY, Wang LE, Guo ZZ, Qiao YW, Zhang L, Zhang W, Mao L, Wei QY: In vitro expression levels of cell-cycle checkpoint proteins are associated with cellular DNA repair capacity in peripheral blood lymphocytes: a multivariate analysis. J Proteome Res 2007, 6:1560-1567.

47. Koo JH, Chae WJ, Choi JM, Nam HW, Morio T, Kim YS, Jang YS, Choi KY, Yang JJ, Lee SK: Proteomic analysis of resting and activated human CD8(+) T cells. J Microbiol Biotechnol 2006, 16:911-920.

48. Bian T, Yin KS, Jin SX, Zhang XL, Zhou JY, Ma XQ, Hu JJ, De W: Treatment of allergic airway inflammation and hyperresponsiveness by imiquimod modulating transcription factors T-bet and GATA-3. Chin Med J (Engl) 2006, 119:640-648.

49. Jeong HC, Lee SY, Lee EJ, Jung KH, Kang EH, Lee SY, Kim JH, Park EK, Lee SH, Uhm CS, Cho YJ, Shin C, Shim JJ, Kim HK, In KH, Kang KH, Yoo SH: Proteomic 
analysis of peripheral T-lymphocytes in patients with asthma. Chest 2007 132:489-496.

50. Ko YC, Hsu WH, Chung JG, Dai MP, Ou CC, Wu WP: Proteomic analysis of CD4+ T-lymphocytes in patients with asthma between typical therapy (controlled) and no typical therapy (uncontrolled) level. Hum Exp Toxicol 2011, 30:541-549.

51. Aron Y, Busson M, Polla BS, Dusser D, Lockhart A, Swierczewski E, Favatier F: Analysis of hsp70 gene polymorphism in allergic asthma. Allergy 1999, 54:165-170.

52. Tong W, Luo W: Heat shock proteins' mRNA expression in asthma. Respirology 2000, 5:227-230.

53. Katsumoto T, Mitsushima A, Kurimura T: The role of the vimentin intermediate filaments in rat 3Y1 cells elucidated by immunoelectron microscopy and computer-graphic reconstruction. Biol Cell 1990, 68:139-146.

54. Korfei M, Schmitt S, Ruppert C, Henneke I, Markart P, Loeh B, Mahavadi P, Wygrecka M, Klepetko W, Fink L, Bonniaud P, Preissner KT, Lochnit G, Schaefer L, Seegar W, Guenther A: Comparative proteomic analysis of lung tissue form patients with idiopathic pulmonary fibrosis (IPF) and lung transplant donor lungs. J Proteome Res 2011, 10:2185-2205.

55. Tallle C, Grootenboer-Mignot S, Boursier C, Michel L, Debray MP, Fagart J, Barrientos L, Mallleux A, Cigna N, Tubach F, Marchal-Somme J, Soler P, Chollet-Martin S, Crestant B: Identification of Periplakin as a new target for autoreactivity in idiopathic pulmonary fibrosis. Am J Respir Crit Care Med 2011, 183:759-766.

56. Ruhrberg C, Hajibagheri MA, Parry DA, Watt FM: Periplakin, a novel component of cornified envelopes and desmosomes that belongs to the plakin family and forms complexes with envoplakin. J Cell Biol 1997, 139:1835-1849,

57. Long HA, Boczonadi V, Mclnroy L, Goldberg M, Maatta A: Periplakindependent re-organisation of keratin cytoskeleton and loss of collective migration in keratin-8-downregulated epithelial sheets. J Cell Sci 2006, 119:5147-5159.

58. van den Heuvel AP, de Vries-Smits AM, van Weeren PC, Dijkers PF, de Bruyn KM, Riedl JA, Burgering BM: Binding of protein kinase $B$ to the plakin family member periplakin. J Cell Sci 2002, 115:3957-3966.

59. Beekman JM, Bakema JE, van de Winkel JG, Leusen JH: Direct interaction between FcgammaRI (CD64) and periplakin controls receptor endocytosis and ligand binding capacity. Proc Natl Acad Sci USA 2004, 101:10392-10397.

60. Jemal A, Siegel R, Ward E, Hao Y, Xu J, Thun MJ: Cancer statistics. CA Cancer J Clin 2009, 59:225-249.

61. Cravatt BF, Simon GM, Yates JR: The biological impact of massspectrometry-based proteomics. Nature 2007, 450:991-1000.

62. Gstaiger M, Aebersold R: Applying mass spectrometry-based proteomics to genetics and network biology. Nat Rev Genet 2009, 10:617-627.

63. Domon B, Aebersold R: Mass spectrometry and protein analysis. Science 2006, 312:212-217

64. Bonk T, Humeny A: MALDI-TOF-MS analysis of protein of protein and DNA. Neuroscientist 2001, 7:6-12.

65. Thiede B, Höhenwarter W, Krah A, Mattow J, Schmid M, Schmidt F, Jungblut PR: Peptide mass fingerprinting. Methods 2005, 35:237-247.

66. Haqqani AS, Kelly JF, Stanimirovic DB: Quantitative protein profiling by mass spectrometry using isotope-coded affinity tags. Methods $\mathrm{Mol}$ Biol 2008, 439:225-240.

67. Han DK, Eng J, Zhou H, Aebersold R: Quantitative profiling of differentiation-induced microsomal proteins using isotope-coded affinity tags and mass spectrometry. Nat Biotechnol 2001, 19:946-951.
68. Gygi SP, Rist B, Berber SA, Turecek F, Gelb MH, Aebersold R: Quantitative analysis of complex protein mixtures using isotope-coded affinity tags. Nat Biotechnol 1999, 17:994-999.

69. Ivaldi C, Martin BR, Kieffer-Jaquinod S, Chapel A, Levade T, Garin J, Journet A: Proteomic analysis of S-acylated proteins in human B cells reveals palmitoylation of the immune regulators CD20 and CD23. PLoS One 2012, 7:e37187.

doi:10.1186/1479-5876-12-6

Cite this article as: Zhou et al:: Proteomic profiling of lymphocytes in autoimmunity, inflammation and cancer. Journal of Translational Medicine 2014 12:6.

\section{Submit your next manuscript to BioMed Central and take full advantage of:}

- Convenient online submission

- Thorough peer review

- No space constraints or color figure charges

- Immediate publication on acceptance

- Inclusion in PubMed, CAS, Scopus and Google Scholar

- Research which is freely available for redistribution 